\title{
Partial reinforcement with a small number of trials: Performance in extinction'
}

Garvin MeCain ARLINGTON STATE COLLEGE

\begin{abstract}
Thirty-eight albino rats were given four acquisition trials in a straight alley. One group received $50 \%$, the other $100 \%$ reinforcement. The $50 \%$ group was more resistant to extinction in terms of running times and latencies. This result was in accord with earlier work and is contrary to predictions from the frustration hypothesis as presently formulated.
\end{abstract}

\section{Problem}

This study is one of a series which utilizes a very limited number of acquisition trials. In two preliminary studies (McCain et al, 1962,1963) partial reinforcement groups were more resistant to extinction than comparable consistent reinforcement groups when each were given only three acquisition trials. This finding was interpreted as contrary to prediction from the frustration hypothesis (Amsel, 1958) and Spences' (1960) analysis of the PRE, which is very similar to Amsel's. The present study provides an opportunity to check the earlier findings using somewhat different techniques. As contrasted to the earlier studies, the present study utilized a different number of acquisition trials and pattern of reinforcement, a longer extinction period, different performance measures, longer intertrial intervals and a different deprivation schedule. Over and above any specific test of theory, another objective of this series is development of techniques for using a limited number of acquisition trials.

\section{Method}

The 40 Ss were 90-day-old albino rats. One $S$ in each group was lost due to experimental error.

The straight alley runway has been more fully described elsewhere (McCain et al, 1962). A photoelectric cell was added to the original equipment $1-1 / 2$ in from the start box door to measure latency.

Food was removed from Ss cages on Day 1. Days 2 through 7 , Ss were fed and handled $1 \mathrm{hr}$. daily. Days 8 through 12, Ss explored the maze. Exploration procedure was the same as in McCain et al, (1962). Day 13, Ss were fed for $30 \mathrm{~min} ., 24 \mathrm{hr}$. before they were to be run on Day 14.

Phase I. All Ss were given four acquisition trials. Group $P(N=19)$ was given an NRNR reinforcement pattern. Group $C(N=19)$ was given four consecutive reinforcements. The criterion for failure to run was a time of over $30 \mathrm{sec}$. on the first acquisition trial but no Ss were dropped on this basis. Ss failing to reach the goal box within 45 sec. on any trial were guided to the goal box. Ss remained in the goal box for 30 sec. with a $30-$ sec. intertrial interval.

$\mathrm{Ph}$ a s e II. Ss were given 12 extinction trials. The only change from Phase I was that Ss remained in the goal box $15 \mathrm{sec}$.

\section{Results}

Figures $1 \mathrm{a} \& \mathrm{~b}$ show running time and latency data for the extinction period. Data were transformed by taking a logarithm of (X sec. +1$)$ from blocks of three trials and were analyzed using a trend analysis (Edwards, 1960). Group $P$ was more resistant to extinction than Group $C$ on both running time $(F=4.01$; df, $1 / 37 ; p<.055)$ and latency $(F=6.88$; df, $1 / 37 ; p<.02)$ measures. There is a significant Groups $\mathrm{x}$ Trials interaction $(F=4.68 ; \mathrm{df}, 3 / 108 ; \mathrm{p}<.005)$ in the analysis of running times. This interaction is due to the convergence of scores on the last block of trials. As noted in the procedure section, there was a 45-sec. maximum running time in extinction. As the groups approach this limit differences between the groups tend to narrow. If

Fig. la \& b. Performance of the groups on extinction trials. 
the first three blocks of trials are analyzed separately the difference between groups is significant $(F=5.00$; df, $1 / 37 ; p<.05)$.

\section{Diseussion}

The data from this study strongly support the McCain et al, $(1962,1963)$ finding that the PRE can be achieved following a very short acquisition series.

In the framework of the frustration hypothesis it is assumed that after $r_{g}$ has been established, nonreinforcement in a partial reinforcement group produces frustration (F). On succeeding trials fractional anticipatory frustration responses $\left(r_{f}\right)$ are present. Ss are trained to approach the goal box in the presence. of these antedating frustration stimuli. Thus the presence of $r_{f}$ during extinction tends to evoke a running response in a partial reinforcement group. It is difficult to see how the series of events assumed to produce the PRE could develop in the small number of acquisition trials used in this and the earlier studies.

Even though the conditions of this study were somewhat different from those of the McCain et al (1962,
1963) studies, it would be rash to assume that these studies eliminate all possibilities of an artifact. Eight additional studies have been completed and should shed further light on the use of a small number of acquisition trials.

\section{References}

AMSEL, A. The role of frustrative nonreward in noncontinuous reward situation. Psychol. Bull., 1958, 55, 102-119.

EDWARDS, A. L. Experimental design in psychological research. (Rev. ed.) New York: Rinehart \& Co., 1960.

MCCAIN, G., LOVE, NANCEY, \& GRUER, W. Extinction as a function of a small number of partially reinforced trials. Psychol. Rep., 1962, 11, 451-454.

McCÁIN, G., REED, CYL, \& McCORMACK, L. Extinction after a small number of partial reinforcement trials. Psychol. Rep., 1963, 13,300 .

SPENCE, K. W. Behavior theory and learning. Englewood Cliffs, N. J.: Prentice-Hall, Inc., 1960.

Note

1. This study was supported by NIMH Grant MH-06981. Thanks are due to Ronald Kuenstler who ran the Ss.

\section{Reply}

Schulman is quite correct in pointing out that the stated value of $\mathrm{E} / \mathrm{N}_{0}$ was too low; the actual value was 9.2 rather than 2.9 as it appears in the article. However, the rest of Schulman's remarks are erroneous.

In paragraph three of Schulman's note he states that our readers were given the false impression that the probability of a correct response, $\operatorname{Pr}(C)$, varies independently of the probability of a yes-response, $\operatorname{Pr}\left(A_{1}\right)$. We fail to see how the relationship could be indicated more clearly than by giving the expressions for $\operatorname{Pr}(C)$ and $\operatorname{Pr}\left(\mathrm{A}_{1}\right)$ which were the only two such equations presented in the article. These equations specify how both quantities depend upon hit and false alarm rates, and make it very clear that they are not independent. The statement that Schulman quotes from our article (which he says gives the erroneous impression that $\operatorname{Pr}(C)$ and $\operatorname{Pr}\left(A_{1}\right)$ vary independently) certainly does not convey the notion of independence to us, nor in our opinion, to anyone who has the most elementary understanding of the concept of statisticall independence.

The most disturbing aspect of Schulman's note is the material presented in the first two paragraphs. We particularly invite the reader to reread the last sentence of Schulman's first paragraph where he "quotes" the article and then to read the actual material in the first paragraph on page two of the article. Schulman indicates that we attempt to establish whether the data points fall on the same ROC curve when in fact we explicitly invite the reader to decide this issue for himself. We reference a model proposed by Atkinson as giving a good account of these data (a model that predicts curvilinear operating characteristics) and state that in our opinion the points fall on the same ROC curve. Our principal reason for presenting the data in such complete form, with 16 statistics for each of 14 subjects, is that different theories will require different types of analyses to establish their adequacy. We presented the data as we did, with no theoretical analysis, because we did not consider a note in Psychonomic Science as an appropriate place to compare alternative theoretical interpretations.

If Schulman is interested in analyzing these data in terms of signal detectability theory or with a linear ROC curve, then a report of the analyses might be worth publishing. However, if he does publish such an analysis we hope that he will not attribute the linear ROC assumption to us. In this regard, Schulman says that our data "are fitted nearly perfectly" by a curvilinear ROC curve of the Tanner-Swets-Green variety. We agree that the fit is extremely good, but if Schulman had used a chi-square test to judge the goodness-of-fit he would have rejected the theoretical function at beyond the $10^{-4}$ level. This remark is not a criticism of signal detectability theory, but a statement designed to point out that any current theory would be rejected on statistical grounds on the basis of our experiment for there were approximately 10,000 observations on each of 14 subjects. None of the current theories are precise enough to withstand a judgment based solely on whether the null hypothesis can be rejected, when such a large number of observations are made.

Except for the incorrect value of the signal-to-noise ratio, we find no basis for Schulman's criticism.

R. A. Kinchla, New York University

R. C. Atkinson, Stanford University 